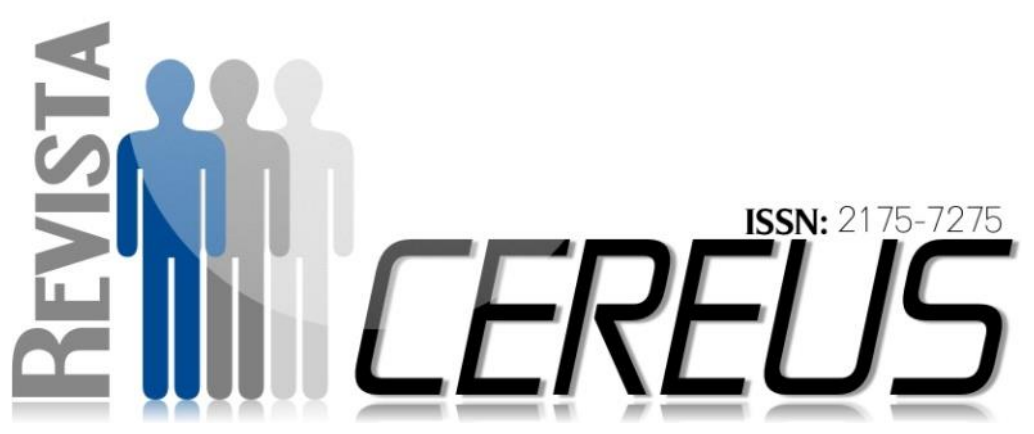

DOI: 10.18605/2175-7275/cereus.v9nep172-188.

\title{
A APLICAÇÃO DO CÓDIGO DE DEFESA DO CONSUMIDOR AOS CONTRATOS CELEBRADOS PELA INTERNET
}

\section{RESUMO}

LIMA, Suelen Rodrigues ${ }^{1}$ MOTA, Gabriel Gama Gonçalves ${ }^{2}$ SILVA, Fábio Araújo²

A sociedade atual se destaca através das relações comerciais feitas pelos seus integrantes que, ante ao capitalismo, acabam por depositar no consumo as satisfações que outros setores não the garantem. Anos atrás, para se adquirir um produto ou mercadoria, o interessado havia que se deslocar até o estabelecimento que fornecesse o produto ou serviço em questão para que então pudesse pagar pelo mesmo. Ocorre que, com a rápida e assustadora evolução cibernética, a internet, que antes se limitava a diminuir os espaços entre as pessoas, com as ferramentas de relacionamento $e$ comunicação, passou também a ser ponto de negociações comerciais. Com as lojas virtuais, não só a oferta e a procura passaram a ser online, mas também a celebração dos contratos. Com isso, uma nova modalidade de contratação

\footnotetext{
${ }^{1}$ Acadêmico do curso de direito do Centro Universitário Unirg ${ }^{2}$ Docentes do curso de direito do Centro Universitário Unirg
} 
surgiu: os contratos celebrados pela internet, fazendo surgir com ele uma dúvida acerca de qual legislação se aplicar a esta espécie sem expressa previsão legislativa. Há, contudo, entendimento segundo o qual se aplica o Código de Defesa do Consumidor, uma vez que as partes integrantes da negociação se enquadram nas definições de consumidor e fornecedor, sendo uma clara relação de consumo, sendo este o objeto de estudo através do método dedutivo da presente pesquisa jurídica.

Palavras-chave: Contratos. Internet. Código de Defesa do Consumidor.

\section{APPLICATION PROTECTION CODE AWARDED CONTRACTS BY INTERNET TO CONSUMERS}

\section{ABSTRACT}

The current company stands out through trade relations made by its members that, compared to capitalism, end up depositing in consumer satisfaction which other sectors do not guarantee it. Years ago to purchase a product or commodity, the applicant had to move to the property to provide the product or service in question and then I could pay for it. It is that with the fast and scary cyber evolution, the Internet, which before was limited to reduce the spaces between people with relationship and communication tools, also became a point of trade negotiations. With online stores, not only supply and demand are now online, but also the conclusion of contracts. With this, a new type of contract has emerged: the contracts concluded on the Internet, giving rise to him a question about which laws apply to this kind without express legislative forecast. There is, however, understanding that applies the Consumer Protection Code, since the members of the negotiating parties fall in consumer settings and supplier, with 
a clear relationship of consumption, which is the object of study by the method deductive of this legal research.

Key Words: Contract. Internet. Consumer protection code. 


\section{INTRODUÇÃO}

O desenvolvimento humano e das tecnologias é um fator notável desde os primórdios da humanidade, tendo se tornado mais latente a partir do Século XIX, fruto da famosa Revolução Industrial, que veio alertar o pensamento social acerca da necessidade de criação de mecanismos de crescimento, a fim de dar mais qualidade de vida a todos os cidadãos.

Hoje em dia praticamente todas as relações humanas foram substituídas por mecanismos virtuais que permitem a conversação e resolução de questões de forma cibernética, sem que para tanto possa haver danos aos interlocutores.Em verdade, quase todos os profissionais têm se utilizado dos instrumentos da internet para facilitar as negociações com seus clientes. Além das propagandas divulgadas pela rede mundial de computadores, é recente a consolidação de vendas.

Nessas situações, assim como nas aquisições presenciais, é necessária a regularização do negócio celebrado, cujo instrumento é o contrato de compra e venda. Isto posto, surge um fato novo no mundo jurídico, qual seja os contratos feitos via internet, cuja elaboração tem gerado controvérsias e adaptações.

A contratação por meio eletrônico é relativamente recente no Brasil, existindo ainda algumas lacunas legislativas a respeito desse tema, demandando um posicionamento do Poder Judiciário Brasileiro acerca da natureza desses contratos.

Além da discussão da natureza da celebração do contrato pela internet, há ainda análise do cabimento das disposições do Código de Defesa do Consumidor (CDC). Desta feita, ainda que o mesmo não tenha explicitamente regulado essa situação, mostra-se necessário observar 0 seu posicionamento e sua previsão jurídica para a resolução de eventuais problemas advindos dessa realidade.

Pretende-se 0 estudo da possibilidade de aplicação do CDC aos contratos virtuais, através do uso do método dedutivo de pesquisa, baseado em vasto material bibliográfico, partindo de uma análise sobre a teoria geral dos contratos; a recente contratação via internet; concluindo-se pelo estudo do direito do consumidor e sua incidência nos contratos eletronicamente 
firmados.

\section{METODOLOGIA}

Para a produção científica, a elaboração do presente estudo se refere à utilização de pesquisa jurídica cujos materiais são essencialmente bibliográficos, uma vez que o assunto a ser estudado se encontra em obras literárias, artigos, periódicos, dentre outros. Para tanto, fundamentaram a produção, os textos disponíveis em livros, bem como em produções independentes acessíveis via rede mundial de computadores.

Sustentam a pesquisa jurídica o material doutrinário dos renomados

\section{RESULTADOS}

3.1EVOLUÇÃO HISTÓRICA DO CÓDIGO DE DEFESA DO CONSUMIDOR

O direito do consumidor como hoje se encontra é fruto de grande crescimento jurídico, o qual culminou na ampla proteção dada aos consumidores, considerados elo mais fraco nas relações de consumo.

O primeiro diploma legal a proteger os consumidores foi o Código de Hammurabi (1728-1686 a.C.), ao autores: Maria Helena Diniz; Fábio Ulhôa Coelho; Carlos Alberto Bittar; Carlos Roberto Gonçalves, entre outros.

Quanto ao método de estudo, tem-se o dedutivo como fundamento, haja vista que a pesquisa se inicia expondo as noções gerais acerca dos contratos, bem como fatores relevantes sobre o Código de Defesa do Consumidor, para somente depois concluir acerca da aplicabilidade do CDC aos contratos celebrados via internet.

prever que médicos, barbeiros, pedreiros, arquitetos, etc., conferindo direitos dos contratantes para com estes profissionais contratados. (NORAT, 2011, p. 03)

Com o passar dos anos, o mundo começou a abrir seus olhos para a necessidade de regulamentação das relações de consumo e proteção dos envolvidos nessas negociações, principalmente dos consumidores que acabavam prejudicados pelos 
desmandos dos comerciantes que agiam a seu bel prazer apenas em benefício próprio.

Em 1985, a Organização das Nações Unidas (ONU) editou a Resolução $n^{\circ}$. 39/248, prevendo o princípio da vulnerabilidade do consumidor, tornando o mesmo merecedor de proteção jurídica especifica, por figurar como parte mais fraca da relação consumerista. (GUGLINSKI, 2013)

No Brasil, a legislação pioneira em defesa dos consumidores foi a Lei da Ação Civil Pública (Lei n. 7.347/85), protegendo os interesses difusos da sociedade. Ainda em 1985, foi criado o Conselho Nacional de Defesa do Consumidor (VIEGAS, 2011, p. 04)

Em 1988, com a promulgação da Carta Cidadã é que o direito do consumidor assumiu status constitucional, estando incluído dentre as disposições do artigo $5^{\circ}$, que elenca os direitos fundamentais de todo cidadão, prevendo que "o Estado promoverá, na forma da lei, a defesa do consumidor". (CF, 1988, art. $5^{\circ}$, inciso XXXII)

Dois anos após a Constituição Federal de 1988, a Lei n . 8.078, de 11 de Setembro de 1990 foi sancionada. Intitulada Código de Defesa do
Consumidor, trata-se da lei que dita as normativas que regulam as relações de consumo no ordenamento jurídico brasileiro, a qual passamos a analisar melhor doravante.

\subsection{ASPECTOS GERAIS DO CÓDIGO DE DEFESA DO CONSUMIDOR}

Sancionado no ano de 1990, o Código de Defesa do Consumidor CDC - é a principal legislação reguladora das relações de consumo brasileiras, ditando as diretrizes que regem a ordem pública, econômica e também de interesse social.

O CDC apresenta como basilares do direito do consumidor os princípios da vulnerabilidade do consumidor; do dever governamental; da garantia de adequação; da boa fé nas relações de consumo; da informação; e do acesso à justiça. (BISINOTTO, 2012, p. 02)

Objetivando a proteção do consumidor, muitas vezes explorado e vitimado pelo fornecedor, o CDC compreende as compras e vendas de produtos; bens duráveis ou não; e contratações de serviços, desde que as partes se enquadrem nas figuras previstas no artigo $2^{\circ}$ e $3^{\circ}$ do CDC:

Art. $2^{\circ}$ Consumidor é toda pessoa física ou jurídica que adquire ou utiliza produto ou serviço como destinatário final. 
Parágrafo único. Equipara-se o consumidor a coletividade de pessoas, ainda que indetermináveis, que haja intervindo nas relações de consumo.

Art. $3^{\circ}$ Fornecedor é toda pessoa física ou jurídica, pública ou privada, nacional ou estrangeira, bem como os entes despersonalizados, que desenvolvem atividade de produção, montagem, criação, construção, transformação, importação, exportação, distribuição ou comercialização de produtos ou prestação de serviços.]

Dentre as disposições do CDC, destaca-se a criação da Política Nacional das Relações de Consumo, melhor explicitada pela estudiosa Edneia Freitas Gomes Bisinotto:

Destarte, o artigo 4ํ do Código de Defesa do Consumidor trata acerca da Política Nacional das Relações de Consumo, com vistas a atender às necessidades dos consumidores, respeitando a saúde, dignidade, segurança, proteção dos interesses econômicos, melhoria da qualidade de vida, visando a transparência e harmonia das relações de consumo. (BISINOTTO, 2012, p. 02)

Do texto do CDC, destacam-se principalmente os direitos do consumidor previstos no seu art. $6^{\circ}$, dentre os quais merecem ênfase os seguintes: a proteção à vida, saúde e segurança; a qualidade e eficiência de produtos e serviços; a educação e divulgação correta acerca dos produtos e serviços vendidos; as informações acerca do consumo adequado, bem como das especificidades do objeto fornecido; e a proteção contra a publicidade enganosa e abusiva. (CDC, art. $6^{\circ}$ )

\section{DOS CONTRATOS}

\subsection{TEORIA GERAL DOS CONTRATOS}

Desde os primórdios da humanidade que os indivíduos vem celebrando entre si pactos, acordos relacionados a determinada finalidade. A essas negociações dá-se o nome de contratos.

A teoria geral dos contratos se inclui no direito das obrigações, conforme nos ensina Roxana Cardoso Brasileiro Borges:

No Direito Civil, a teoria geral dos contratos (e os contratos em espécie) faz (fazem) parte do Direito das Obrigações [03]. O que se chama de direito contratual é, na verdade, direito obrigacional. Não há, na topologia do Código Civil, tanto no de 1916 como no de 2002, um livro próprio para a teoria geral dos contratos, nem para os contratos em espécie. O que há, na Parte Especial, é o Livro das Obrigações (Livro I), o primeiro livro da Parte Especial. Este ramo do direito civil contém as normas sobre a teoria geral das obrigações, a teoria geral dos contratos, os contratos em espécie, os atos unilaterais e a responsabilidade civil. Pode-se entender, ainda, que, com a inclusão do tratamento dos títulos de crédito e do Direito de Empresa, estes 
também se encontram no Direito das Obrigações que, com o Código Civil de 2002 foi unificado (esta unificação é contestada por alguns). (BORGES, 2005, p. 01)

Segundo Maria Helena Diniz:

Contrato é o acordo de duas ou mais vontades, na conformidade da ordem jurídica, destinado a estabelecer uma regulamentação de interesses entre as partes, com o escopo de adquirir, modificar ou extinguir relações jurídicas de natureza patrimonial. (DINIZ, 2008, p. 30)

Para que seja dotado de validade, o contrato deverá ser constituído por agentes capazes; objeto lícito, possível e determinado; e de forma prescrita ou não proibida em lei (art. 104, Código Civil, 2002).

A celebração de contratos em território nacional está alicerçada em vários princípios gerais de direito, dentre os quais merecem destaque: da boa fé contratual; da função social do contrato; da autonomia de vontade dos contratantes; do consensualismo; e da supremacia da ordem pública. (DIAS, p.01)

Como visto a teoria geral dos contratos, com previsão no Código Civil, trazem em seu bojo os regramentos que delimitam todas as negociações celebradas, trazendo várias outras disposições acerca do assunto. Eis aqui uma apertada síntese do essencial.

\subsection{DOS TIPOS DE CONTRATOS}

No ordenamento pátrio admitem-

se uma série incontável de contratos, os quais possuem diversas classificações, dentre as quais se destacam as abaixo analisadas.

Quanto à natureza das obrigações assumidas, pode ser: a) unilateral: apenas uma das partes está obrigado a algo; b) bilateral: ambos se obrigam; c) gratuitos: um dos contratantes tem ônus enquanto o outro apenas benefícios; d) onerosos: ambos contratantes têm deveres; e) comutativos: um dos envolvidos recebe do outro uma contraprestação e imediatamente se apropria da mesma; f) aleatórios: obrigações incertas quando da elaboração do termo; g) paritários: igualdade entre contratantes, que discutem os termos do contrato; e h) de adesão: ausente a liberdade de contratação, de modo que um dos contratantes aceita as cláusulas previamente impostas pelo outro.(GOMES, 2013, p.02)

Em relação às pessoas, poderá ser pessoal ou impessoal. O primeiro considera as características do indivíduo, sendo somente o mesmo capaz de executar as obrigações Rev. Cereus, v. 9, n. esp, p.172-188, ago-dez./2017, UnirG, Gurupi, TO, Brasil. 
assumidas. Será impessoal, por outro lado, quando qualquer pessoa, com capacidade para fazê-lo, consiga executar as atribuições firmadas em contrato.(DONZELE, 2011, p.01)

Quanto à forma, tem-se: a) contratos consensuais, firmados após aprovação de proposta pelas partes; b) reais, que prescindem da entrega de coisa pra se consolidar; c) solenes, se aperfeiçoando apenas com a sua elaboração na forma prevista em lei; d) verbal, sem transcrição em termos; e) por instrumento particular: feito por escrito pelas partes; e f) por instrumento público: termo escrito realizado perante tabelião. (GOMES, 2013, p.03)

\subsection{DOS CONTRATOS FEITOS PELA INTERNET}

Nos tempos atuais, assim como muitas outras atividades cotidianas, a celebração de negócios jurídicos migrou para o meio virtual, criando uma nova espécie de contrato: os contratos feitos pela internet.

O contrato celebrado via internet pode se definir como sendo "o encontro de uma oferta de bens ou serviços que exprime de modo audiovisual através de uma rede internacional de telecomunicações e de uma aceitação suscetível de manifestar-se por meio da interatividade". (MIRANDA, 2014, p. 01) De forma mais ampla, Luis Wielewick completa:

Ainda que sucintamente os
contratos eletrônicos pode ser
definidos como instrumentos
obrigacionais de veiculação
digital, são todas as espécies
de signos eletrônicos
transmitidos pela Internet que
permitem a determinação de
deveres e obrigações jurídicos
(WIELEWICK apud LEAL,
2007, p. 78-79)

Quanto à classificação, os contratos eletrônicos se subdividem em três espécies: intersistêmicos, interpessoais e interativos. Os primeiros são aqueles instrumentos que as cláusulas já estavam prontas, sendo o computador apenas um meio de execução dele. São interpessoais os contratos cujas partes interagem virtualmente, através do envio de mensagens eletrônicas. Por fim, os contratos interativos, também denominados contrato por clique, são aqueles nos quais o contratante aceita todos os termos através da confirmação digital. Muito comuns atualmente, os contratos interativos são um exemplo notável do contrato de adesão previsto no art. 54 do CDC.(SANTE, 2013, p.03)

\section{A formação desta relação} jurídica inicia-se através da oferta e Rev. Cereus, v. 9, n. esp, p.172-188, ago-dez./2017, UnirG, Gurupi, TO, Brasil. 
procura que, nesses casos, ocorre através do comércio eletrônico, com a divulgação de produtos e preços respectivos, o qual pode ser alcançado através da consulta no site da loja virtual e/ou após a busca nos mecanismos de pesquisa que apontam os melhores preços e condições. A consolidação do mesmo se dá através da aceitação do comprador que, geralmente, se dá após um clique, podendo também ser possível as negociações nas formas indicadas no parágrafo anterior.

Sobre a validade jurídica de tais contratos, Fabrina Bastos Cabral do Rosário leciona:

Para ter validade o contrato eletrônico deve preencher alguns requisitos legais exigidos pelo Código Civil, como: A exigência da manifestação da vontade de duas ou mais pessoas capazes civilmente para a efetivação do ato do contrato, é importante que não apresente vícios de consentimento e sociais; A licitude e a possibilidade física ou jurídica do objeto e conteúdo econômico; A exigência do uso do computador na sua formação, ficando registrado no seu disco rígido, podendo ser transferido para homepages, CD-ROMs, etc., servindo como meio probatório. Contudo, o posicionamento adotado pela maioria da doutrina é de que os contratos eletrônicos devem ser juridicamente considerados válidos e eficazes, desde que cumpridos algumas condições importantes ao meio magnético em que são transmitidos. (ROSÁRIO, 2012, p.01).

Mais relevante que todo 0 exposto, é a legislação aplicável a tal forma de contratação, já que não há hoje uma lei específica, há um enorme entendimento pela aplicabilidade do Código de Defesa do Consumidor aos contratos virtuais. Sobre o tema, passa se a expor.

\section{5 - DA APLICABILIDADE DO CDC NOS CONTRATOS VIRTUAIS}

Com a ausência de previsão expressa, o Código de Defesa do Consumidor seria o dispositivo de lei aplicável aos negócios jurídicos celebrados através do uso da internet, quando enquadrados na definição de relação de consumo, já exemplificada.

O primeiro ponto a ser considerado é que os contratos virtuais decorrem do comércio eletrônico, que pode ser definido como sendo "a utilização de tecnologias de informação avançadas, para 0 aumento de eficiência nas relações comerciais e para o desenvolvimento de contratos de maneira geral, quer entre empresas, quer entre pessoas físicas." (LIMA,2010, p. 18)

A modernidade trouxe as pessoas para 0 meio virtual, transferindo para o mesmo toda sorte Rev. Cereus, v. 9, n. esp, p.172-188, ago-dez./2017, UnirG, Gurupi, TO, Brasil. 
de situações antes realizadas apenas fisicamente, tornando o comércio eletrônico mais atrativo, já que no conforto de sua residência o contratante tem possibilidade de analisar todas as ofertas, de modo a escolher a que melhor se apresente aos seus anseios.

\section{Considerando que os contratos} virtuais nada mais seriam que uma forma diversa de contratação entre consumidor e consumidor, elucida:

\begin{abstract}
Atualmente, é comum para grande parte dos consumidores a negociação pela rede mundial de computadores. Entretanto, as relações realizadas através da internet encontram amparo nas disposições legais vigentes, principalmente as que se referem ao Código de Defesa do Consumidor. Vale destacar que o artigo 13 do projeto de lei no 1589/99 (OAB/SP, 1999) dispõe que "aplica-se ao comércio eletrônico as normas de defesa e proteção do consumidor". (LIMA, 2010, p. 18-19)
\end{abstract}

Para o mestre Fábio Ulhoa Coelho "a circunstância de a venda ter se realizado num estabelecimento físico ou virtual em nada altera os direitos dos consumidores e os correlatos deveres dos empresários" (COELHO, 2006, p.42).

Seguindo a mesma corrente, Carlos Alberto Bittar dispõe:

[...] é possível adequar de forma satisfatória as relações virtuais às atuais leis Rev. Cereus, v. 9, n. esp, p.172-188, ago-dez./2017, UnirG, Gurupi, TO, Brasil. brasileiras, eis que os contratos pela internet se formam da mesma forma que os contratos tradicionais (negociações preliminares, proposta, aceite), sendo que a única diferença entre ambos é o meio por onde se desenvolvem. Por esta mesma razão o comércio eletrônico também se submete às disposições do Código de Defesa do Consumidor, sem maior esforço hermenêutico, o que é ponto pacífico na doutrina brasileira (BITTAR, 2003, p. 20).

Outro fator que determina o uso das disposições do CDC consiste na previsão civil de que se interpretem os contratos de forma favorável ao aderente. Sobre o argumento, melhor ensina Patrícia Marangoni de Lima:

O artigo 423 do Código Civil prevê que nos contratos por adesão, existindo cláusulas ambíguas ou contraditórias, deverá ser adotada a interpretação mais favorável ao aderente.

O Código de Defesa do Consumidor adotou o mesmo princípio, conforme disciplina o artigo 47.

Os incisos do artigo 51 do mesmo diploma indicam as situações em que cláusulas notadamente abusivas são tidas como nulas, demonstrando a preocupação do legislador em proteger o consumidor vulnerável na relação comercial. Esta proteção deverá ser aplicada aos contratos firmados eletronicamente, nas situações em que se identificam consumidor e fornecedor. (LIMA, 2014, p.01)

O fato é que tanto o Código de Defesa do Consumidor quanto 0 Código Civil não regulam 
especificamente o contrato eletrônico, pois no tempo em que foram editados, o comércio eletrônico não era tão forte quanto se é hoje.

\section{Consubstanciados nestes} argumentos supra, da leitura e análise dos julgamentos recentes sobre questões que discutem as disposições de contratos celebrados no meio eletrônico, percebe-se que opta pela aplicação do CDC, tendo em vista que mencionado diploma legal estabelece normas de ordem pública, qualificadas como cogentes e indisponíveis. Aliada às normas consumeiristas, aplica-se também as normas contratuais do Código Civil Brasileiro. (SOUZA, 2015, p.02)

Neste sentido, alguns julgados exemplificativos:

AÇÃO CIVIL PÚBLICA. BEM MÓVEL. CONTRATO DE ADESÃO. COMPRA E VENDA DE BEM POR MEIO ELETRÔNICO. INFORMAÇÃO A RESPEITO DE PRAZO DE ENTREGA DO PRODUTO E DA MORA DO FORNECEDOR. MULTA MORATÓRIA PARA AMBAS AS PARTES. EQUILÍBRIO CONTRATUAL QUE SE IMPÕE. DIREITO DE ARREPENDIMENTO NO PRAZO DE REFLEXÃO. ART. 49 DO CDC. DEVOLUÇÃO IMEDIATA DA QUANTIA PAGA. MULTA EM CASO DE ATRASO POR PARTE DA FORNECEDORA. Todo contrato de consumo deve trazer, necessária e claramente, o prazo de cumprimento das obrigações do fornecedor. Se é estipulada multa moratória para o consumidor inadimplente, com razão a fixação de penalidade para o fornecedor que não cumpre a sua obrigação no prazo estabelecido, sob pena de desigualdade e rompimento do equilíbrio contratual. Demonstrado efetivamente acerca dos prazos e condições do contrato de adesão para as compras efetuadas no portal virtual da empresa e que a entrega das compras efetuadas em seu site depende da localização em que se encontra 0 consumidor, despicienda a condenação para impor referido prazo. A imposição de multa para somente uma das partes configura evidente desequilíbrio contratual que fere o disposto no art. 51, inc. IV, § 1.․․, inc. II, do CDC. Assim, a fim de tornar o contrato equilibrado para ambas as partes, razoável de multa para o caso de descumprimento do prazo de entrega da mercadoria por parte do fornecedor, no montante de $2 \%$ do preço do produto, quantia que corresponde à penalidade imposta ao consumidor em caso de inadimplemento. A imposição de multa e prazo para a restituição dos valores pagos durante 0 prazo de reflexão tem a mesma finalidade que a multa fixada para atraso na entrega da mercadoria, ou seja, inadimplência no cumprimento da obrigação por parte do fornecedor. Recurso parcialmente provido. (TJ-SP APL: 02254134720088260100 SP

47.2008.8.26.0100, Relator: Gilberto Leme, Data de Julgamento: 16/07/2013, $27^{\mathrm{a}}$ Câmara de Direito Privado, Data de Publicação: 22/07/2013)

TRIBUNAL DE JUSTIÇA DO ESTADO DO RIO DE JANEIRO DÉCIMA SEGUNDA

Rev. Cereus, v. 9, n. esp, p.172-188, ago-dez./2017, UnirG, Gurupi, TO, Brasil. 
CÂMARA CÍVEL APELAÇÃO CÍVEL $\quad n^{\circ} \quad$ 000631781.2011.8.19.0209

APELANTE:

PONTO

FIRIO.COM COMÉRCIO

ELTRÔNICO S.A. APELADO:

BIANCA PETROLONGO

SILVA PINTO RELATORA:

DES. LÚCIA MARIA MIGUEL

DA SILVA LIMA APELAÇÃO

CÍVEL. COMPRA PELA

INTERNET. LOJA VIRTUAL.

ESPECIFICAÇÃO

PRODUTO QUE NÃO

ADEQUADO AO

CONSUMIDOR. DIREITO DE

ARREPENDIMENTO. ART. 49

C.D.C. DEMORA

INJUSTIFICADA DE

RESSARCIMENTO DO

VALOR PAGO. FALHA NA PRESTAÇÃO DO SERVIÇO. RESPONSABILIDADE CIVIL. DANO MORAL. CARÁTER PUNITIVO E PEDAGÓGICO. Nas compras realizas fora do estabelecimento comercial da fornecedora de produtos, é conferido ao consumidor o direito de arrependimento, vez que o consumidor não tem a certeza de que está adquirindo um produto com as especificações e dimensões necessárias ao seu uso. A compra e venda utilizando a internet apresenta-se como uma realidade nos dias atuais, de modo a impor ao fornecedor a modernização e eficiência adequada para o cumprimento de sua obrigação. A situação privilegiada que estes se encontram, vez que apenas enviam os produtos comprados com o pagamento prévio do preço pelo consumidor, deve ser acompanhada de um dever de realizar a pronta restituição do valor pago quando da não concretização do negócio. A demora de meses para a devolução do valor despendido gera dano moral, que deve compreender um caráter punitivo pedagógico. Conhecimento do recurso e seu desprovimento, nos termos do art. 557, caput do C.P.C. (TJ-RS. Apelação Cível no

Rev. Cereus, v. 9, n. esp, p.172-188, ago-dez./2017, UnirG, Gurupi, TO, Brasil.
0006317-81.2011.8.19.0209.

Relatora: Des. Lúcia Maria Miguel Da Silva Lima. Julgamento: 17/01/2012)

Isto posto, quando a contratação celebrada via internet for feita por um individuo identificado como consumidor, no outro lado um fornecedor, e essa negociação se referir à uma relação de consumo, a aplicação do CDC se impõe uma vez que, protege todos contratos feitos nessa situação, protegendo o hipossuficiente contra os desmandos dos vendedores de produtos e serviços.

\section{CONSEQUÊNCIAS SOCIAIS E JURÍDICAS DO CONSUMIDOR FRENTE AO CONTRATO} VIRTUAL

\subsection{DAS CONSEQUÊNCIAS JURÍDICAS E SOCIAIS}

Assim como todos outros fatores da vida comum, também a celebração de contratos através do meio virtual ocasiona alterações nos cotidianos das pessoas, causando algum efeito, que pode ser tanto positivo como negativo.

No âmbito social, a facilitação na aquisição de produtos e serviços certamente é a maior consequência, que gerou também o consumo por parte dos interessados que, com o 
comodismo, acabam por aceitar as propostas dos fornecedores, mesmo sem estar procurando pelo produto, mas que, diante da propaganda, aproveita a oportunidade.

Há um faturamento maior para os fornecedores, enquanto os consumidores acabam por se endividar. Além disso, as lojas físicas perdem um pouco do espaço antes dominado por eles, causando a demissão de parte dos funcionários.

Por outro lado, há uma renovação constante, com a evolução dos setores comerciais, que, são

\section{CONSIDERAÇÕES FINAIS}

Como a evolução tecnológica é mais veloz que a jurídica, no ordenamento pátrio, não há ainda expressa previsão de qual diploma regularia as contratações celebradas através do uso da internet, delimitando a forma como deveriam ser feitas e os princípios específicos dessas negociações.

Todavia, sendo certo que não há como esperar uma atitude legislativa para a que seja dada uma prestação judicial a todos os problemas levados à apreciação do julgador togado, há uma tendência incitados a todo tempo, a apresentarem melhores preços, haja vista que, a internet permite ao contratante fazer a comparação de produtos e ofertas.

No âmbito jurídico, as consequências seriam a insegurança jurídica acerca de qual diploma legal se aplicariam ao caso proposto, regulamentando a contratação através do meio eletrônico. Nesse ponto, a jurisprudência veio e consolidou a aplicação do CDC quando se reconhece a relação de consumo entre contratante e contratado.

enquadramento das questões às leis já vigentes, adequando aos detalhes que diferenciam cada forma de contratação.

Neste sentido, o Código de Defesa do Consumidor se mostra apto a regular os contratos celebrados via internet quando os mesmos se referirem a uma relação de consumo, cabendo ao juiz da causa, considerar as especificidades que 0 meio cibernético apresenta. Em casos de lacuna no CDC, aplica-se subsidiariamente as lições do Código Civil, quanto ao direito contratual: 
elementos, requisitos de validade $\mathrm{e}$

efeitos, dentre outros fatores.

\section{REFERÊNCIAS}

BISINOTTO, Edneia Freitas Gomes. Breves considerações sobre o Código de Defesa do Consumidor. In: Âmbito Jurídico, Rio Grande, XV, n. 104, set 2012. Disponível em: <http://www.ambito-juridico.com.br/site/?n link=revista art igo s leitura\& artigo id=11906>. Acesso em set 2016;

BITTAR, Carlos Alberto. Direitos do Consumidor: Código de Defesa do Consumidor. Rio de Janeiro: Forense Universitária, 2003;

BORGES, Roxana Cardoso Brasileiro. A atual teoria geral dos contratos. Revista Jus Navigandi, Teresina, ano 10, $\underline{n}$. 811, $22 \underline{\text { set. } 2005}$. Disponível em: <https://jus.com.br/artigos/7267>. Acesso em: 5 set. 2016;

BRASIL. Constituição da República Federativa do Brasil de 1988. Disponível em: $<$ http://www.planalto.gov.br/ccivil 03/Constituicao/Constituicao.htm>. Acesso em 10 de ago de 2016;

BRASIL. Lei $\mathbf{n}^{\circ}$. 10.406, de 10 de janeiro de 2002. Institui o Código Civil. Disponível em:<http://www.planalto.gov.br/ccivil_03/leis/2002/L10406.htm>. Acesso em 02 set. de 2016;

BRASIL. Lei $\mathbf{n}^{\circ}$. 8.078, de 11 de Setembro de 1990. Institui o Código de Defesa do Consumidor. Disponível em: <http://www.planalto.gov.br/ccivil 03/leis/L8078.htm>. Acesso em: 01 de set. de 2016;

BRASIL. Tribunal de Justiça de São Paulo - TJ-SP - APL: 02254134720088260100 SP 0225413-47.2008.8.26.0100, Relator: Gilberto Leme, Data de Julgamento: 16/07/2013, 27aㅡ Câmara de Direito Privado, Data de Publicação: 22/07/2013;

BRASIL. Tribunal de Justiça do Rio de Janeiro - TJ-RS. Apelação Cível oㅡ 000631781.2011.8.19.0209. Relatora: Des. Lúcia Maria Miguel Da Silva Lima. Julgamento: 17/01/2012;

COELHO, Fábio Ulhoa. Curso de Direito Comercial. 6 ed. São Paulo: Saraiva. 2006;

DIAS, Jorge. Teoria Geral do Contratos resumo teoria geral dos contratos resumo. Disponível em: <http://www.ebah.com.br/content/ABAAAgPrAAl/teoria- 
geral-contratos-resumoteoria-geral-dos-contratos-resumo>. Acesso em 01 de set. 2016;

DINIZ, Maria Helena. Curso de direito civil brasileiro. Vol. 3. São Paulo: Saraiva, 2008;

DONZELE, Patrícia. Contratos pessoais e impessoais. Publicado em 06 de setembro de 2011.2 Disponível em: <http://profpatriciadonzele.blogspot.com.br/2011/09/contratos-pessoais-eimpessoais.html>. Acesso em 01 de nov. 2016;

GOMES, Paulo César. Direito Civil: classificação dos contratos. Publicado em 04 de abril de 2013. Disponível em: $<$ http://professorpaulocesar.blogspot.com.br/2013/04/direito-civil-classificacaodos.html>. Acesso em 28 out. 2016;

GONÇALVES, Carlos Roberto. Direito Civil brasileiro. Volume III: contratos e atos unilaterais. 5. ed. São Paulo: Saraiva, 2008;

GUGLINSKI, Vitor. Breve histórico do Direito do Consumidor e origens do CDC. Jusbrasil, 2013. Disponível em: <http://vitorgug.jus brasil.com.br/artig os/11210659 6/breve-historico-do-direito-do-consumidor-e-origens-do-cdc $>$. Acesso em 02 de set. de 2016;

LEAL, Sheila do Rocio Cercal Santos. Contratos Eletrônicos: validade jurídica dos contratos via internet. São Paulo: Editora Atlas. 2007;

LIMA, José Edvald \{http://www.conteudojuridico.com.br/artigo,a-tutela-dos-contratosde-consumo-eletronicos-no-ordenamento-juridico-brasileiro,52929.html\} o Albuquerque de. A Aplicação do Código de Defesa do Consumidor nos Contratos Eletrônicos. Faculdade Paraibana, 2010. Disponível em: <http://www.fappb.edu.br/instituto/arquivos/artigo_aplicacao_codigo_defesa_do_con sumidor_contratos_eletronicos_Jose_Edvaldo.pdf>. Acesso em 29 out. 2016;

LIMA, Patrícia Marangoni. Aplicação do Código de Defesa do Consumidor e do Decreto 7.962/2013 aos Contratos Eletrônicos. Jusbrasil, 2014. Disponível em: $<$ http://patriciamarangoni.jusbrasil.com.br/artigos/129100765/aplicacao-do-codigode-defesa-do-consumidor-e-do-decreto-7962-2013-aos-contratos-eletronicos>.

Acesso em 30 de out. 2016;

MIRANDA, Janete. Contratos Eletrônicos - princípios, condições e validade. Jusbrasil, 2014.2 Disponível em: $<$ https://jan75.jusbrasil.com.br/artigos/149340567/contratos-eletronicos-principioscondicoes-e-validade>. Acesso em 02 nov. 2016; 
NORAT, Markus Samuel Leite. Evolução histórica do Direito do Consumidor. In: Âmbito Jurídico, Rio Grande, XIV, n. 88, maio 2011. Disponível em: $<$ http://www.ambito-juridico.com.br/sit e/index.ph $\quad \mathrm{p}$ ?n link=revista a rtigos leitura\&artigo id=9474>. Acesso em set 2016;

ROSÁRIO, Fabrina Bastos Cabral do. A validade jurídica dos contratos pela internet. FBV,01 de junho de 2012. Disponível em: <http://idireitofbv.wikidot.com/contratos>. Acesso em 03 nov. 2016;

SANTE, Paulo Henrique Vieira. Contratos eletrônicos e sua validade jurídica. In: Âmbito Jurídico, Rio Grande, XVI, n. 118, nov 2013. Disponível em: $<$ http://ambito-

juridico.com.br/site/?n link=revista artigos leitura\&artigo $\mathrm{id}=13867$ \& revista cadern

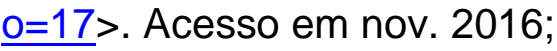

SOUZA, Taciara de Almeida. A tutela dos contratos de consumo eletrônicos no ordenamento jurídico brasileiro. Conteúdo Jurídico, 03 de abril de 2015. Disponível em: <http://www.conteudojuridico.com.br/artigo,a-tutela-dos-contratos-de-consumoeletronicos-no-ordenamento-juridico-brasileiro,52929.html>. Acesso em 30 out. 2016;

VIEGAS, Cláudia Mara de Almeida Rabelo; ALMEIDA, Juliana Evangelista de. A historicidade do Direito do Consumidor. In: Âmbito Jurídico, Rio Grande, XIV, n. 90, jul 2011. Disponível em: <http://www.ambito-juridico.co m.br/site/inde x.php?n link=revista artigos leitura\&artigo id=9820\&revista caderno=10>. Acesso em set 2016. 